\title{
CUESTIONES ACTUALES SOBRE LA CUSTODIA COMPARTIDA
}

\author{
Alejandro Andrés Martín Molina \\ Abogado y Doctorando de la Universidad de Granada \\ Email: 4207@icagr.es
}

RESUMEN: El presente trabajo trata de analizar las últimas novedades en materia de custodia compartida, especialmente aquellas relativas a las tendencias jurisprudenciales más recientes, así como su problemática principal

PALABRAS CLAVE: Custodia compartida, corresponsabilidad, visita

\begin{abstract}
The present paper tries to analyze the latest developments in shared custody, especially those related to recent jurisprudential tendencies, as well as its main problematic
\end{abstract}

KEY WORDS: Shared custody, co-responsibility, visit

En materia del régimen de custodia compartida, ha sido el Tribunal Supremo el órgano jurisdiccional que empezó a implantar este nuevo sistema de forma normalizada y preferente. Así, por ejemplo, la Sentencia nº 623/2009 de 8 Octubre de 2009 (RJ 2009/4606), establece la doctrina esencial en esta materia, consistente en la utilización de criterios tales como la práctica anterior de los progenitores en sus relaciones con el menor y sus aptitudes personales; los deseos manifestados por los menores competentes; el número de hijos; el cumplimiento por parte de los progenitores de sus deberes en relación con los hijos y el respeto mutuo en sus relaciones personales y con otras personas que convivan en el hogar familiar; los acuerdos adoptados por los progenitores; la ubicación de sus respectivos domicilios, horarios y actividades de unos y otros; el resultado de los informes exigidos legalmente, $y$, en definitiva, cualquier otro 
que permita a los menores una vida adecuada en una convivencia que forzosamente deberá ser más compleja que la que se lleva a cabo cuando los progenitores conviven.

Para poder aplicar este sistema debe atenderse principalmente al criterio que tengan sobre esto los progenitores de los menores, sobre todo si es compartido dicho criterio y no existen controversias sobre las medidas que se van a adoptar en aras de procurar el mejor bienestar de sus hijos menores y que redunde en su desarrollo personal y de relación con sus padres. No debe imponerse en estos casos la decisión del Juez ni aunque venga avalada con el criterio favorable del Ministerio Fiscal y ello porque las personas que realmente conocen la situación personal de cada familia son los cónyuges o integrantes de una pareja de hecho. Este criterio de toma de decisiones por los miembros de una pareja, ante todo, teniendo en cuenta que deben ser ellos quienes tengan que valorar las posibilidades y consecuencias en la forma en que se van a regir desde el momento de la separación con sus hijos, es el que entiendo correcto y el que debe ser prioritario en las resoluciones judiciales en las que al menos exista un criterio compartido por ambas partes contendientes. Dicho esto con toda la salvedad que deba aplicarse en aquellos casos en los que el consenso de los progenitores pueda perjudicar por acción u omisión en alguna forma a los menores, situación para la cual debe ser prioritario y predominante, a pesar de lo que digan los padres, el dictamen del Ministerio Fiscal y por último la decisión que ponderando los intereses en juego tenga que adoptar el Juez para asignar la guarda y custodia.

Afirma ROMERO COLOMA que si bien gran parte de la doctrina se refiere al «interés» del hijo, o a su «beneficio», considera que la dicción correcta, la que mejor se ajusta a los parámetros que deben regir en materia de Derecho de Familia, es la de «bienestar» del hijo. No cabe duda que, por regla general -hay que exceptuar, naturalmente, los supuestos anómalos, a los que se les puede calificar de «patógenos»-, los hijos quieren estar con su madre y con su padre, y una medida familiar como lo es la guarda y custodia compartida, no cabe duda, propicia que las relaciones de ambos progenitores con sus hijos no se deterioren, evitando, debido a su periodicidad, a su frecuencia, que los hijos se distancien, gradualmente, de uno de los progenitores, por lo general, del progenitor con el que, de no adoptarse esta medida, no conviven. ${ }^{1}$ 
También considera ANGELES ZUÑIGA que el sistema de custodia compartida conllevará mayores beneficios para los menores, como pueden ser mejores resultados académicos, mejor adaptación, mayor autoestima, madres menos sobrecargadas, y evitación del conflicto, porque los hijos dejan de convertirse en la moneda de cambio. ${ }^{2}$

Las resoluciones judiciales han ido estableciendo este régimen de custodia compartida como el criterio que debe ser aplicado actualmente en aras de proteger y tratar de forma igualitaria los derechos de los dos progenitores en una ruptura de pareja, donde lo que se rompe es la convivencia matrimonial o de pareja pero no la relación, la estancia o el cariño con los hijos de sus padres y viceversa que debe mantenerse tal como era durante la convivencia familiar pero ahora de forma distinta.

En este momento de la vida de todo niño que pase por ello, va a ser imprescindible una buena explicación de la situación por la que atraviesan sus padres y posiblemente, en muchos casos, un apoyo psicológico para que los menores superen dicho trance con el menor daño posible en sus vidas, para que su evolución como personas sea plena y sin traumas de ningún tipo.

Los hijos deben ser excluidos de dicha problemática y debe establecerse una forma de relación con ambos padres de la misma forma que era hasta entonces y debiendo tener igual intensidad en cuanto al tiempo de estancia con los mismos y del afecto que se les transmita.

Los tribunales de justicia poco a poco están dictando sus resoluciones en el sentido de ir aplicando el sistema de guarda y custodia compartida como el sistema preferente, y solo en aquellos casos en los que no sea posible su aplicación, se procederá a adjudicar la custodia a uno de los progenitores y al otro un régimen de visitas normalizado.

1 ROMERO COLOMA A. M. Doctora en Derecho. Abogada. Profesora de Derecho de Familia y Sucesiones. Publicación: Actualidad Jurídica Aranzadi num. 814/2011 parte Opinión. Editorial Aranzadi, S.A.U., Cizur Menor. 2011.

2 ZUÑIGA Angeles. La custodia compartida. Revista jurídica “escritura pública”. Dialnet, ISSN 1695$6508, N^{\circ} .78,2012$, págs. 64-66 
Por ejemplo, se puede destacar la resolución dictada por el Tribunal Superior de Justicia de Aragón en la Sentencia no 18/2013 de 25 de marzo, donde se declara que la custodia compartida es el régimen preferente y predeterminado por el legislador, en busca del interés del menor, de modo que se aplicará esta forma de custodia siempre que el padre y la madre estén capacitados para el ejercicio de las facultades necesarias a tal fin. El Derecho foral de dicha comunidad autónoma establece este régimen como preferente frente al criterio general establecido en el Código Civil.

En la distinta casuística jurisprudencial podemos encontrar resoluciones como la Sentencia de la Sala $1^{a}$ del Tribunal Supremo de 14 de octubre de 2015 (RJ 2015, 4746), donde se establece una custodia compartida por semanas para el padre y la madre. Este criterio de custodia compartida se acuerda por nuestro Alto Tribunal en contra de las sentencias del Juzgado de Primera Instancia de Madrid y de la Audiencia Provincial de Madrid que establecieron la guarda y custodia para la madre. Criterio éste que nos lleva a pensar en un cambio jurisprudencial por parte del Tribunal Supremo a la hora de aplicar regímenes de custodia diferentes a los tradicionales, más acordes con los tiempos actuales y con las nuevas formas de vida y de trabajo y relaciones sociales. Adoptar un sistema de custodia compartida por semanas supone que previamente entre los cónyuges debe haber habido una buena relación y una correcta comunicación para poder llevar a cabo la misma. Ello es debido a que los cambios por semanas de los menores de un domicilio a otro deben hacerse y estar previstos para que los mismos no sufran ningún trastorno en su cotidiana forma de vida y su adaptación al nuevo régimen de vida sea lo menos traumático posible. Para ello, los domicilios de los progenitores deben tener una cierta cercanía y una adaptación para los menores de forma similar en cuanto a sus espacios de estudio, así como que exista cercanía con el colegio. Evidentemente, esto se puede evitar si el régimen de custodia semanal se lleva a cabo en el mismo domicilio familiar y son los progenitores los que entran y salen del mismo cada vez que les corresponda ejercer la custodia de sus hijos. Esta forma va a suponer un mayor trastorno para los cónyuges pero para los menores va a ser más beneficioso porque no van a ver alterada su forma de vida ni su estancia en el hogar familiar, pudiendo desarrollar la misma vida en la medida de lo posible que estaban llevando a cabo antes de la ruptura de sus padres. Criterio seguido actualmente por la Sala $1^{\text {a }}$ del Tribunal Supremo en sus Sentencias núm. 135/2017 de 28 febrero (JUR 2017\53344) y la núm. 110/2017 de 17 febrero (RJ 2017\483). 
Como afirma PANIZA FULLANA, si bien el Código civil regula algunos aspectos generales de la guarda y custodia compartida, no ha previsto qué ocurre con la atribución del uso de la vivienda familiar. Vuelven a chocar, en supuestos como este, el derecho de propiedad con el derecho de uso de la vivienda que fue familiar después de la ruptura de la pareja. ${ }^{3}$

Existe también una discusión en torno la conveniencia de decretar una custodia compartida con residencia principal o privilegiada o custodia compartida con residencia alternada o un sistema de residencia única para los hijos e indistinto para los padres (“sistema de anidación”). LATHROP GÓMEZ. ${ }^{4}$

En este punto el TS ha dicho que la interpretación del art. 92,5, 6 y 7 CC debe estar fundada en el interés de los menores que van a quedar afectados por la medida que se va a tomar de guarda y custodia compartida y que se acordará cuando concurran algunos de los requisitos fijados por dicho Tribunal y recogidos como doctrina jurisprudencial en la Sentencia de 29 de abril de 2013 (RJ 2103, 3269), de forma que debe estar fundada en el interés de los menores que van a quedar afectados por la medida que se deba tomar, que se acordará cuando concurran una serie de criterios que determinen como era la convivencia con los menores antes de la separación, teniendo en cuenta los hijos que existan en el matrimonio o la pareja de hecho y la forma de relacionarse entre ellos; debiendo tener en consideración los informes que emitan los especialistas que analicen a los menores, sobre todo si están vinculados al juzgado competente.

\footnotetext{
${ }^{3}$ PANIZA FULlANA A.; Profesora Titular de Universidad de Derecho Civil. Universidad de las Illes Balears. Magistrada Suplente de la Audiencia Provincial de las Illes Balears. Publicación: Revista Doctrinal Aranzadi Civil-Mercantil num. 10/2015 parte Comentario. Editorial Aranzadi, S.A.U., Cizur Menor. 2015.
} 
Nuestro Tribunal Supremo afirma que la redacción del artículo 92 no permite concluir que se trate de una medida excepcional, sino que, al contrario, habrá de considerarse normal e incluso deseable, porque permite que sea efectivo el derecho que los hijos tienen a relacionarse con ambos progenitores, aun en situaciones de crisis, siempre que ello sea posible y en tanto en cuanto lo sea. ${ }^{5}$

Como se deja consagrado en la STS de 19 de julio de 2013 (RJ 2013/5002), lo que se prima es el interés del menor, tratando de lograr una forma de convivencia lo más similar posible a la que existía antes de la ruptura matrimonial y este interés exige una colaboración de los progenitores tendente a que este tipo de situaciones se resuelvan en un marco de normalidad familiar que termine con los conflictos familiares tanto desde la relación del progenitor no custodio con sus hijos, como de estos con aquel, en los casos en los que existe un cónyuge custodio y otro no custodio.

Situaciones en las que, como en esta sentencia, es preciso interponer una demanda de modificación de medidas para lograr cambiar el régimen de custodia existente.

No obstante, en primera instancia no se logró cambiar dicho régimen ni en el recurso de apelación, pero sí se admitió el recurso de casación por el Supremo, otorgándose un nuevo régimen de custodia compartida, a desarrollar por quincenas y suprimiendo la pensión alimenticia, con lo que cada progenitor debería hacerse cargo del mantenimiento y manutención de sus hijos cuando estén con cada uno y el abono de los gastos extraordinarios se realizaría por mitad por ambos.

Este cambio de custodia se acuerda incluso contra el dictamen en contra de un informe psicológico que expone que los menores se encontraban bien bajo la custodia de la madre y con el régimen de visitas del padre.

\footnotetext{
${ }^{4}$ LATHROP GÓMEZ, Fabiola. Custodia compartida de los hijos. La Ley, Madrid, 2008. 582 pp.

${ }^{5}$ STS de 25 de abril de 2014; (RJ 2014/2651).
} 
No obstante, lo que valora y tiene en cuenta el Tribunal Supremo para cambiar la sentencia en casación es que los menores tienen un vínculo afectivo positivo y normalizado tanto con la madre como con el padre, no presentando preferencias por ninguno de los dos. Lo cual supone que, a pesar de estar los menores bien con el régimen que tienen hasta ahora, no existe ningún obstáculo para que la custodia se lleve a cabo de forma compartida cada quince días. Se tiene muy en cuenta en casos como éste el hecho de que ambos progenitores sean personas muy capaces de llevar a cabo el debido y correcto cumplimiento de la custodia compartida, presentando un alto grado de interés por el mejor bienestar de sus hijos y, sobre todo, porque para conseguir un mayor desarrollo afectivo y una estabilidad emocional de los menores es deseable lograr el entorno más armónico posible, que garantice el derecho de los hijos de contar con una madre y un padre afianzando los vínculos de afecto y apego de ambos progenitores.

Para UREÑA MARTÍNEZ la aportación más valiosa, que realiza la STS de 19 de julio de 2013, es que refuerza la tendencia actual pro custodia compartida, al modificar la medida de guarda exclusiva - que estaba funcionando bien-, con el argumento de que el favor filii en la sociedad actual exige un compromiso mayor y una colaboración entre los progenitores: se prima el interés del menor y este interés, que ni el artículo 92 del Código Civil ni el artículo 9 de la Ley orgánica 1/1996, de 15 de enero, de Protección Jurídica del Menor, definen ni determinan, exige sin duda un compromiso mayor y una colaboración de los progenitores tendente a que este tipo de situaciones se resuelvan en un marco de normalidad familiar que saque de la rutina una relación simplemente protocolaria del padre no custodio con sus hijos que, sin la expresa colaboración del otro, termine por desincentivarla tanto desde la relación del no custodio con sus hijos, como de estos con aquel. ${ }^{6}$

\footnotetext{
${ }^{6}$ UREÑA MARTÍNEZ M. Profesora Titular de Derecho Civil en la Universidad de Castilla-La Mancha. Publicación:Revista Cuadernos Civitas de Jurisprudencia Civil num. 94/2014 parte Sentencias. Editorial Civitas, SA, Pamplona. 2014.
}

${ }^{7}$ DELGADO DEL RÍO G. Catedrático de Derecho Eclesiástico de la Universidad de las Islas Baleares. Publicación: Monografías (Civitas). La custodia de los hijos: la guarda compartida: opción preferente. BIB 2010\3063. Editorial Aranzadi, S.A.U., Enero de 2010. ISBN978-84-470-3532-8 
Podemos llegar a la conclusión, por tanto, de que es determinante que una de las premisas más importantes que se exige para acordar la custodia compartida es que exista muto acuerdo entre las partes o, al menos, buena relación; no obstante, no es requisito imprescindible dicho acuerdo, sino más bien una voluntad decidida y razonable vinculada al desarrollo del menor, al igual que unas aptitudes y cualidades para el diálogo entre los progenitores que beneficie a los menores.

Para DELGADO DEL RÍO al enfrentarse con el hecho de reconocer o no una guarda compartida, la jurisprudencia viene exigiendo, como condición «sine qua non», la necesidad de acreditar en los progenitores una determinada actitud, una específica capacidad para el entendimiento, para el diálogo, para la comunicación y para la cooperación mutua. De lo contrario el sistema de guarda compartida se convertirá en una fuente de enfrentamientos, de conflictos, de problemas en el ámbito familiar y en la relación entre todos sus componentes. En tal caso, el interés de los menores aconseja un sistema de guarda exclusiva. $^{7}$

Por ello, no se va a dejar de adoptar dicha custodia si no se cumplen tales requisitos de forma completa, al no ser requisitos sine qua non, sino premisas deseables. Así, podemos señalar como la STS no 545/2016, de 16 de septiembre (RJ 2016/4449) admite el motivo casacional de un padre solicitando la custodia compartida y lo motiva diciendo que la interpretación del artículo 92, 5, 6 y 7 del Código Civil debe estar fundada en el interés de los menores que van a quedar afectados por la medida que se deba tomar de guarda y custodia compartida, que se acordará cuando concurran algunos de los criterios reiterados por esta Sala y recogidos como doctrina jurisprudencial en la Sentencia de 29 de abril de 2013 (RJ 2013/3269).

Para los supuestos en los que concurran distintos intereses legítimos en juego y no puedan ser respetados todos a la par, deberá de primar en todo caso el interés superior del menor.

Es por ello por lo que el Tribunal Supremo accede en dicha Sentencia 545/2016 al otorgamiento de la custodia compartida y corrige así las resoluciones de los tribunales inferiores, Audiencia Provincial y Juzgado de Primera Instancia, sobre la base de que en la sentencia que se recurre se infringe la doctrina jurisprudencial puesto que no se analiza la necesidad o no de la custodia compartida sino que se limita a valorar las 
ventajas del mantenimiento del status quo. Señala el Alto Tribunal que con el establecimiento del régimen de custodia compartida se consiguen una serie de efectos favorables para el menor y sus progenitores como son:

a) se fomenta la integración del menor con ambos padres, evitando desequilibrios en los tiempos de presencia;

b) se evita el sentimiento de pérdida;

c) no se cuestiona la idoneidad de los progenitores;

d) se estimula la cooperación de los padres, en beneficio de los menores, que ya se ha venido desarrollando con eficiencia.

En consecuencia, fija una forma de custodia en la que, a falta de acuerdo, el reparto del tiempo de custodia será semanal y con un periodo vacacional a mitades iguales para ambos progenitores.

Entrelazado con este régimen de custodia está el tema de la vivienda familiar que afecta también al menor y, por ello, al acordarse la custodia compartida, los menores ya no deberán residir habitualmente en el domicilio de la madre, sino que con periodicidad semanal habitarán en el domicilio de cada uno de los progenitores, no existiendo ya una residencia familiar, sino dos, por lo que ya no se podrá hacer adscripción de la vivienda familiar, indefinida, a los menores y al padre o madre que con ellos convivan, pues la residencia ya no es única; en virtud del art. $96.2 \mathrm{CC}$, aplicado analógicamente, a la vista de la paridad económica de los progenitores, se determina que la madre podrá mantenerse en la vivienda que fue familiar durante un año, computable desde la fecha del dictado de la sentencia del Supremo, con el fin de facilitar a ella y a los menores (interés más necesitado de protección), la transición a una nueva residencia (STS 9 de septiembre de 2015), transcurrido el cual la vivienda quedará supeditada al proceso de liquidación de la sociedad de gananciales. Así, pues, se fija el plazo de un año para que la madre abandone la vivienda conyugal. 
Criterios a tener en cuenta al establecer un régimen de custodia compartida son los referentes a la edad de los hijos, la proximidad de los domicilios de los progenitores, la disponibilidad en cuanto al aspecto laboral y a tiempos para estar con los menores por parte de los progenitores, o el ambiente en el que estarán dichos menores como son las nuevas relaciones con amigos, vecinos o la continuidad con su entorno escolar o familiar. $^{8}$

Para GARCÍA GARNICA de esta forma se garantiza que los menores lleven una forma de convivencia después de la ruptura, lo más parecida posible a la que tenían cuando estaban conviviendo con ambos progenitores, al poder mantener una equiparable relación con ambos. ${ }^{9}$

Es consecuencia de lo establecido con el nuevo régimen de custodia compartida, la cuestión de la pensión alimenticia, materia en la que cuando haya semejanza en la percepción de ingresos por ambos progenitores, no existe obligación de abonar pensión de alimentos, conforme se establece dicho criterio en la sentencia de la Audiencia Provincial de León, Sección Segunda, de 24 de marzo de 2014, la sentencia de la Audiencia Provincial de Castellón, Sección Segunda, de 10 de febrero de 2014, las sentencias de la Audiencias Provincial de Islas Baleares, Sección Cuarta, de 14 de mayo de 2013, 19 de mayo de 2014, las sentencias de la Audiencia Provincial de Vizcaya, Sección Cuarta, de fechas 28 de marzo de 2014 y 3 de marzo de 2014. Y en contra, con un criterio jurídico coincidente entre sí y dispar del anterior encontramos la sentencia de la Audiencia Provincial de Navarra, Sección Segunda, de 25 de marzo de 2013, la sentencia de la Audiencia Provincial de Zaragoza, Sección Segunda, de 23 de julio de 2012 y la sentencia de la Audiencia Provincial de Sevilla, Sección Segunda, de 30 de

\footnotetext{
${ }^{8}$ ORTUÑO MUÑOZ, Pascual: “El nuevo régimen jurídico...” Op. Cit., pp. 56-57.

${ }^{9}$ GARCÍA GARNICA, María del Carmen. "Protección de los menores en los procesos de separación y divorcio”. Editorial Aranzadi. Primera Edición. Navarra. España. 2008, pag. 52.
}

junio de 2011, las cuales establecen la obligación de abonar alimentos aun 
cuando se haya establecido el régimen de guarda y custodia compartida. Por ello, la Sala de lo Civil del Tribunal Supremo fija su jurisprudencia en este punto en el sentido que ambos progenitores satisfarán directamente los alimentos del menor en su propio domicilio, abonando los gastos ordinarios y extraordinarios al 50\%. Por lo tanto, existiendo una jurisprudencia contradictoria entre distintas Audiencias Provinciales, se hizo necesario que el Tribunal Supremo en casación fijase la jurisprudencia correcta y la que debía ser seguida por las distintas Audiencias y órganos judiciales en las siguientes demandas que se le presentasen relativas a custodias de menores de edad. Con ello, se consolida la jurisprudencia que en estos casos ha establecido el Tribunal Supremo.

La jurisprudencia del Tribunal Constitucional, que ha sido recogida también por el Tribunal Supremo, ha supuesto un cambio de visión extraordinario hasta el punto de establecer que el sistema de custodia compartida debe considerarse normal y no excepcional, unido ello a las amplias facultades que la jurisprudencia del Tribunal Constitucional fijó para la decisión de los tribunales sobre esta materia, sin necesidad de estar vinculados al informe favorable del Ministerio Fiscal. Ello porque el Tribunal Constitucional en Sentencia $n^{\circ}$ 185/2012, de 17 de octubre (RTC 2012/185) declaró inconstitucional y nulo el inciso "favorable" del informe del Ministerio Fiscal, de tal forma que corresponde exclusivamente al Juez o Tribunal verificar si concurren los requisitos legales para aplicar este régimen. Es por tanto al Juez al que, en el marco de la controversia existente entre los progenitores, corresponde valorar si debe o no adoptarse tal medida considerando cuál sea la situación más beneficiosa para el niño; y si bien se confiere a los progenitores la facultad de autorregular tal medida y el Ministerio Fiscal tiene el deber de velar por la protección de los menores en este tipo de procesos, sólo a aquel le corresponde la facultad de resolver el conflicto que se le plantea, pues exclusivamente él tiene encomendada constitucionalmente la función jurisdiccional, obligando a los progenitores a ejercerla conjuntamente sólo cuando quede demostrado que es beneficioso para el menor. Así lo afirmó PÉREZ CONESA, C., cuando concluyó que lo que realmente vulnera la plena potestad jurisdiccional es un informe desfavorable del Ministerio Fiscal. Siendo favorable, el Juez podrá acordar o denegar la custodia compartida si estima que acordándola o denegándola se protege el interés superior del menor. Es en el caso de ser desfavorable el dictamen del Fiscal en el que quedará limitada la exclusividad y plenitud del ejercicio de la potestad jurisdiccional, puesto que no podrá decretarla a pesar de que valore dicho régimen de 
guarda como el más idóneo para proteger el interés del menor. ${ }^{10}$

El informe del Ministerio Fiscal debe valorarse, por tanto, junto con los demás medios de prueba, al no ser requisito imprescindible que sea favorable. HERNANDO RAMOS. ${ }^{11}$

Como afirmaba la ya citada STS 257/2013 de 29 de abril que establece doctrina esencial sobre la materia, la continuidad del cumplimiento de los deberes de los padres hacia sus hijos, con el consiguiente mantenimiento de la potestad conjunta, resulta sin duda la mejor solución para el menor por cuanto le permite seguir relacionándose del modo más razonable con cada uno de sus progenitores, siempre que ello no sea perjudicial para el hijo, desde la idea de que no se trata de una medida excepcional, sino que, al contrario, debe considerarse la más normal, porque permite que sea efectivo el derecho que los hijos tienen a mantener dicha relación.

El artículo 92 del CC -STS 19 de abril de 2012- establece dos posibilidades para que pueda acordarse la guarda y custodia compartida: la primera es la contenida en el apartado 5, que la atribuye cuando se dé la petición conjunta por ambos progenitores. La segunda se contiene en el apartado 8 de esta misma norma, que permite "excepcionalmente y aun cuando no se den los supuestos del apartado cinco", acordar este tipo de guarda "a instancia de una de las partes", con los demás requisitos exigidos. En ambos casos, un requisito esencial para acordar este régimen es la petición de uno, al menos, de los progenitores: si la piden ambos, se aplicará el apartado quinto, y si la pide uno solo y el juez considera que, a la vista de los informes exigidos en el apartado octavo, resulta conveniente para el interés del niño, podrá establecerse este sistema de guarda.

${ }^{10}$ PÉREZ CONESA, C., «Inconstitucionalidad del inciso "favorable” del artículo 92.8 del Código Civil (LEG 1889, 27) relativo a la custodia compartida solicitada por un solo cónyuge ( STC 17 de octubre de 2012 [RTC 2012, 185] )» en Revista Doctrinal Aranzadi Civil-Mercantil, enero 2013, nº 9. p. 67.

11 HERNANDO RAMOS, Susana. El informe del Ministerio Fiscal en la guarda y custodia compartida. Diario La Ley, ISSN 1989-6913, Nº 7206, 2009.

El Código Civil, por tanto, exige siempre la petición de al menos uno de los 
progenitores, sin la cual no podrá acordarse. No obsta a lo anterior, sigue diciendo, lo dicho en la Sentencia 614/2009, de 28 septiembre, porque si bien es cierto que, de acuerdo con lo establecido en el art. $91 \mathrm{CC}$, el Juez debe tomar las medidas que considere más convenientes en relación a los hijos, en el sistema del Código Civil para acordar la guarda y custodia compartida debe concurrir esta petición al menos por uno de los cónyuges.

Este sistema está también recogido en el art. 80 del Código de Derecho foral de Aragón (Decreto Legislativo 1/2011, de 22 de marzo). A pesar de ello, existen otras soluciones legales, como la contemplada en los números 1 y 2 del art. 5 de la Ley 5/2011, de 1 de abril, de la Generalitat Valenciana de Relaciones Familiares de los hijos e hijas cuyos progenitores no conviven, pero no es precisamente lo que determina el Código Civil.

El Tribunal Supremo viene insistiendo en que las sentencias recaídas en procesos en que se discute la guarda y custodia compartida han de valorar correctamente el principio de protección del interés del menor, motivando suficientemente, a la vista de los hechos probados, la conveniencia de que se establezca o no este sistema de guarda. ${ }^{12}$

Como se afirma en la STS 96/2015 de 16 febrero (RJ 2015/564), esta línea jurisprudencial del Alto Tribunal reacciona frente a aquellas sentencias de instancia que no tienen en cuenta más que aparentemente y de una forma retórica el interés del menor; esa invocación superficial no es suficiente para justificar la negativa al establecimiento de la guarda y custodia compartida pedida únicamente por uno de los progenitores. Lo que se pretende es aproximar este régimen al modelo de convivencia existente antes de la ruptura matrimonial y garantizar al tiempo a sus padres la posibilidad de seguir ejerciendo los derechos y obligaciones inherentes a la potestad o

\footnotetext{
${ }^{12}$ Así las SSTS de 28 de septiembre de 2009, 8 octubre de 2009, 7 julio de 2011, 21 de julio de 2011, 22
} de julio de 2011, 27 de septiembre de 2011, 9 de marzo de 2012 y 29 de abril de 2013.

responsabilidad parental y de participar en igualdad de condiciones en el 
desarrollo y crecimiento de sus hijos, lo que parece también lo más beneficioso para ellos (STS de 2 de julio de 2014).

Por ello, la custodia compartida conlleva como premisa fundamental la necesidad de que entre los padres exista una relación de mutuo respeto que permita la existencia de actitudes y conductas que beneficien en última instancia al menor, que no perturben su desarrollo emocional y que, pese a la ruptura afectiva de los progenitores, se mantenga un marco familiar de referencia que sustente un crecimiento armónico de su personalidad.

Finalmente, debemos referirnos al contenido del artículo 92.7 del Código Civil, donde se regulan los supuestos de conflicto entre los progenitores, en los que no se podrá optar por la custodia compartida, puesto que dicho apartado dispone que «no procederá la guarda y custodia conjunta cuando cualquiera de los padres está incurso en un proceso penal incoado por atentar contra la vida, la integridad física, la libertad, la integridad moral o la libertad o indemnidad sexual del otro cónyuge o de los hijos que convivan con ambos. Tampoco procederá cuando el Juez advierta, de las alegaciones de los padres y las pruebas practicadas, la existencia de indicios fundados de violencia doméstica».

En una materia tan sensible como es la violencia doméstica, no solo de género sino también la que pueda afectar a los menores, no puede conllevar la concesión de derechos y beneficios para quien tiene como forma de vida la violencia y la intimidación, ya sea sobre su cónyuge o sobre sus hijos.

Como afirma BERROCAL LANZAROT ante supuestos de violencia de género el propio artículo 92.7 del Código Civil impide acordar la guarda y custodia compartida.

Por todo ello, en aras de preservar el bienestar de convivencia y la integridad física y moral, es justo y razonable suprimir los derechos de relación del progenitor que ejerza tales actos sobre su cónyuge o sus hijos en tanto tales situaciones desaparezcan y con la intervención de las adecuadas terapias, se reviertan tales situaciones y la persona con estas formas de actuación, modifique su forma de vida y deje de utilizar la violencia

física y moral como un instrumento de manipulación y control sobre su cónyuge, 
Revista Internacional de

su pareja o sus hijos. 